\title{
ERA UMA VEZ UM CONTO DE FADAS: DAS ORIGENS À CONTEMPORANEIDADE
}

\author{
Cinthia Freitas de Souza \\ Mestra em Letras/Estudos literários pela Unimontes \\ ccinthiafs@gmail.com
}

\section{RESUMO}

Este artigo trata do gênero literário conto de fadas e objetiva apresentar a história de produção dessa narrativa, partindo de suas raízes na tradição oral até suas versões escritas, quando ela deixou de pertencer unicamente ao Folclore e tornou-se Literatura efetivamente. Esses contos foram incorporados ao acervo cultural brasileiro por intermédio dos portugueses; contudo, a partir da modernidade, eles passaram a ser muito criticados por sua previsibilidade, estereótipos, e, consequentemente, poucos escritores brasileiros aventuraramse a escrevê-los. Em contrapartida, destacamos a escritora Marina Colasanti, que se dedicou a criar seus próprios contos de fadas. Por isso, analisaremos um de seus contos, chamado "A primeira só", do livro Uma ideia toda azul. Sendo este um estudo de caráter bibliográfico, apoiar-nos-emos em teóricos, como Cascudo (2012), Marina Colasanti (2016, 2004), Mariza Mendes (2000), Nelly Novaes Coelho $(1987,1991)$ e Eliade (1972).

Palavras-chave: Tradição, folclore, contos de fadas, Marina Colasanti.

\begin{abstract}
This paper addresses the literary genre fairy tale and aims at presenting the production history of these texts $s_{L}$ from their roots on the oral tradition to their written versions, when they ceased to belong exclusively to Folklore and became Literature effectively. The Portuguese incorporated these tales into the Brazil culture; however, from modernity on, they started to be widely criticized due to their predictability and stereotypes, and, consequently, few Brazilian writers ventured to write them. In contrast, we highlight the author Marina Colasanti, who dedicated herself to create her own fairy tales, reason why we will analyze one of her tales, "A Primeira Só", from the book Uma Ideia Toda Azul. Since this is a bibliographic study, it is supported by theorists, such as Cascudo (2012), Marina Colasanti (2016, 2004), Mariza Mendes (2000), Nelly Novaes Coelho $(1987,1991)$, and Eliade (1972).
\end{abstract}

Keywords: Tradition, folklore, fairy tale, Marina Colasanti.

\section{CONSIDERAÇÕES INICIAIS}


O primeiro longa-metragem de animação do cinema foi Branca de Neve e os sete anões, lançado pela companhia The Walt Disney em 1937, adaptação de um dos contos de fadas mais famosos da tradição, baseado na versão escrita pelos irmãos Grimm no século XIX. Desde então, houve inúmeras adaptações dos mais conhecidos contos de fadas no cinema. Entretanto, devido às mudanças na estrutura social e política, além da revolução tecnológica, as versões tradicionais dos contos de fadas passaram a ser muito criticadas e perderam sua força; não caíram, porém, no esquecimento.

Esses contos voltaram a ser resgatados pelo cinema, mas, muitas vezes, por meio de recriações, que desconstruíam os aspectos "previsíveis" desses contos, dando-lhes nova roupagem. Destacamos aqui Shrek (2001), Branca de Neve e o caçador (2012), Frozen (2013), Malévola (2014), A Bela e a Fera (2017); e não podemos deixar de mencionar, ainda, a série norte-americana de televisão Once upon a time (2011-2018).

Quanto à produção literária, pouquíssimos escritores aventuram-se a escrevê-los na contemporaneidade. Vale ressaltar que encontramos autores que, por meio da intertextualidade, produziram inúmeras paródias desses contos, mas não se identificaram como sendo autores de contos de fadas a partir da modernidade. Desse período, destacamos, porém, a escritora Marina Colasanti, que se dedicou a produzir seus próprios contos de fadas, por meio de uma linguagem simbólica e poética, reflexiva e questionadora.

Dessa forma, percebemos que os contos de fadas tradicionais não morreram e, por isso, se tornaram acervo cultural enraizado na memória coletiva, inclusive no Brasil, embora essas histórias tenham sido introduzidas no país pelos portugueses.

Nessa perspectiva, este artigo objetiva apresentar as origens dos contos de fadas a partir da tradição oral até a escrita, e como eles se tornaram literatura infantojuvenil. 
Finalmente analisaremos o conto de fadas moderno "A primeira só", de Marina Colasanti, presente em Uma ideia toda azul, publicado inicialmente em 1979, visto que essa escritora é a principal representante da produção desse gênero literário no país, a fim de estabelecer uma relação entre esse conto de fadas moderno e os contos de fadas tradicionais.

\section{DE UM REINO MUITO DISTANTE}

A visão que temos hoje é a de que os contos de fadas são histórias apenas para crianças. Além disso, seus personagens parecem estereotipados e representariam, muitas vezes, uma função social definida culturalmente. Para tratar dessa questão, precisamos entender antes quando surgiram os contos de fadas, quando apareceu a literatura para criança e como se estruturam essas histórias, para não mantermos uma visão às vezes preconceituosa quanto a esse gênero literário.

Comecemos pela origem desses contos. Não é possível definir uma data precisa, mas há um consenso entre os estudiosos de que as histórias que hoje chamamos de contos de fadas

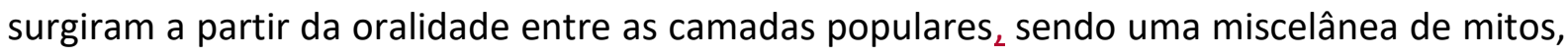
lendas e acontecimentos históricos. Desse modo, de acordo com Patrícia Bastian Alberti (2006), esses contos são um somatório de elementos históricos, simbólicos, sociais e psicológicos de linguagem rica. Sendo oriundos das classes populares, os autores eram anônimos. Assim, ainda segundo a autora,

durante muitos séculos, eles [os contos de fadas] não foram escritos; sobreviveram e se espalharam por toda parte através da memória e da habilidade narrativa de gerações de contadores de histórias, que dedicavam parte das longas noites contando e ouvindo histórias (ALBERTI, 2006, p. 23). 
Desse modo, as famosas versões escritas pelo francês Charles Perrault, pelos alemães Jacob e Wilhelm Grimm e pelo dinamarquês Hans Christian Andersen são resultado de um trabalho de pesquisa da tradição oral pertencente ao folclore.

Nesse contexto, Mariza Mendes (2000) também reforça que há consenso entre os pesquisadores ao defenderem que essas narrativas têm origem na tradição oral. Segundo ela, "as histórias que hoje conhecemos como 'contos maravilhosos', 'contos de magia' ou 'contos de fadas' são remanescentes da tradição mitológica, e os mitos se originaram dos rituais praticados nas tribos primitivas" (MENDES, 2000, p. 22-23).

A pesquisadora, partindo do livro As raízes históricas do conto maravilhoso (1983), de Vladimir Propp, corrobora a ideia de que haveria uma relação direta entre os rituais de iniciação, práticas religiosas de povos primitivos e a origem dos contos feéricos. Desse modo, as ações presentes nessas histórias, como heróis perseguidos, donzelas raptadas, viagens a cavalo e renascimentos corresponderiam à sequência de provas pelas quais passava o iniciado.

Esses ritos, que eram contados pelos mais velhos, tornaram-se posteriormente mitos, e estes se transformaram em contos populares ao longo do tempo. Esse processo, ainda segundo Mariza Mendes, pode ter sido natural ou artificial, provocado, por exemplo, pelas influências que esses povos sofreram devido às constantes invasões. Consequentemente, "os mitos passaram a ser narrados em ambientes comuns (lares, praças públicas) e tornaram-se simples histórias de entretenimento, perdendo seu significado primitivo" (MENDES, 2000, p. 25).

Nesse contexto, de acordo com Mircea Eliade (1972), o que distingue o mito do conto é que o primeiro era considerado verdadeiro e sagrado, de conteúdo religioso. Já o segundo 
seria um desdobramento dos mitos, mas entendido como sendo "história falsa", que trata da aventura de um herói/heroína. Para o autor, o inconsciente é permeado dessas histórias (pensamento e imagens simbólicas), visto que existem "resíduos mitológicos" na psique humana.

Nesse sentido, percebemos, portanto, que os contos de fadas e maravilhosos se tornaram resíduos mitológicos ou, numa perspectiva da teoria junguiana, representam "arquétipos sociais", uma vez que são matérias que parecem fazer parte da sociedade desde sempre, passados de geração em geração inconscientemente.

\section{HISTÓRIA DE CRIANÇA?}

Como dito anteriormente, os contos de fadas e maravilhosos têm suas raízes na oralidade e são definidos, por Luís da Câmara Cascudo (2012), como literatura oral, pertencentes ao folclore. De acordo com o autor, esse termo surgiu em 1881, através dos estudos do folclorista francês Paul Sébillot, durante o Romantismo. Segundo Cascudo, a literatura oral compreende produtos como provérbios, adivinhações, contos, frases-feitas e cantigas.

Ele apresenta quatro requisitos para que uma produção seja incorporada ao folclore, a saber, a antiguidade, a persistência, o anonimato e a oralidade. Assim, "para que seja folclórica, é preciso certa indecisão cronológica, um espaço que dificulte a fixação no tempo. Pode-se dizer a época, uma época extensa, mas não a restringindo" (CASCUDO, 2012, p. 14). Esses fatores são encontrados nos contos de encantamento, se considerarmos sua procedência na oralidade. 
Quando escritos, há consenso de que o primeiro a registrar os contos de fadas foi o francês Charles Perrault, quando, em 1697, lançou o livro Histórias ou narrativas do tempo passado com moralidades, que ficaria conhecido posteriormente sob o título Contos da mamãe Gansa. Quanto ao fato de ter sido o precursor desses contos, Mariza Mendes discorda e defende que, na época em que Perrault lançou seu livro de contos de fadas, contos semelhantes já haviam sido escritos e publicados por escritoras.

Essa ideia é corroborada por Nelly Novaes Coelho (1991), ao afirmar que "a moda das fadas" na França se deve ao livro História de Hipólito, publicado em 1690 (sete anos antes dos Contos da mamãe Gansa, de Perrault). Esse livro, escrito por uma jovem baronesa, Mme. D’ Aulnoy, tem como protagonista uma fada, mas seu reconhecimento, entretanto, não se deu, simplesmente por ser mulher (essa controvérsia é muito interessante e mereceria ser discutida em trabalho específico).

Fato é que, quando passaram a ser escritos, os contos de fadas sofreram diversas alterações. Sobre isso, Marlúcia Nogueira Dodo (2010, p. 47) afirma que "depois dos Contos da mamãe Gansa, de Charles Perrault, os contos de fadas sofreram profundas transformações em seu conteúdo". Essa ideia é reforçada por Lucimar Bresciani, segundo a qual,

os contos tradicionais foram modificados, sofrendo cortes e até mesmo alterações no enredo, porque sua forma original foi considerada inadequada às crianças. Tais textos objetivavam transmitir uma -mensagem moralizante aos infantes, como se vê em Perrault (BRESCIANI, 2010, p. 16).

Os contos de fadas passaram então a ser reescritos a fim de atender à nova concepção de infância que se criava na sociedade, e, assim, surgia a "literatura infantil"; desse modo, foi preciso adaptar essas histórias para que elas pudessem ser lidas pelas crianças. Sendo 
oriundos da tradição oral, os contos de fadas e maravilhosos eram contados por adultos para adultos e crianças, sem distinção, uma vez que a ideia que temos de infância hoje surgiu somente no século XVIII.

Nessa perspectiva, segundo Phillipe Ariès (1981), não havia sequer roupas apropriadas para essa fase da vida. Meninos e meninas usavam roupas de adultos. A adequação do vestuário começa a ocorrer a partir do século XVII, período em que começam a aparecer livros voltados para as crianças.

De acordo com Regina Zilberman (1990), a percepção de infância surgiu influenciada por mudanças econômicas e sociais, tais quais, a Revolução Industrial, a ascensão da burguesia e o surgimento do proletariado, a expansão da vida urbana e a concepção de família nuclear (mãe, pai e filhos).

No Brasil, a literatura infantil surge apenas no século XIX, embora já existissem as traduções dos contos de fadas europeus, incorporados aqui pelos portugueses através de livros chamados Contos de Trancoso. Nessa época, segundo Ana Maria Clark Peres (2007), houve incentivos dos médicos higienistas para se construir o conceito de "família e costumes familiares", a fim de lutar contra a indiferença dos pais através da criação de hábitos educacionais de disciplina e domesticação. Essa ideia de "constituição familiar" fica evidenciada pela primeira edição de livro de contos dos irmãos Grimm, em 1812, chamado Contos de fadas para as crianças e a família. Entretanto, segundo Marina Colasanti (2004, p. 239), os folcloristas lançaram uma segunda edição especial para as crianças, "atenuando a versão original, acrescentando coisas e enriquecendo a narrativa para torná-la mais apetitosa a jovens paladares." 
Outro célebre nome que aparece quando pensamos em conto de fadas é o do dinamarquês Hans Christian Andersen. Assim como Perrault e os irmãos Grimm, o escritor pesquisou o folclore de seu povo e coletou as histórias. Entretanto, o que o diferencia dos outros é o fato de criar novos personagens, além de sofrer influência romântica, fazendo com que suas narrativas fossem filtradas pelo sentimentalismo e espírito cristão, em que “predomina, em geral, um ar de tristeza e dor" (COELHO, 1991, p. 77), como percebemos em "A pequena sereia", que não se casa com o príncipe no final da história, e em "A pequena vendedora de fósforos" (que morre de fome e frio no inverno rigoroso da época do Natal).

Vale lembrar que as primeiras manifestações de literatura infantil nacional no Brasil devem-se a Olavo Bilac, nacionalista ufanista que tentava incutir nas crianças o amor à pátria; todavia, o pai da literatura infantil brasileira é considerado Monteiro Lobato. Entre a produção de contos de fadas modernos no país, destacamos Marina Colasanti, que se dedicou a escrever seus próprios contos de fadas.

\section{CONTO DE FADAS OU CONTO MARAVILHOSO?}

Vale reforçar que entendemos que "contos de fadas" e "contos maravilhosos", embora muito semelhantes, são gêneros literários diferentes, corroborando a teoria proposta por Nelly Novaes Coelho (1991).

A pesquisadora distingue um conto do outro pela origem e problemática. Os contos de fadas teriam surgido entre os celtas, em forma de poemas que tratavam principalmente das várias manifestações do amor. Esse povo vivia inicialmente na região da Ásia, porém, devido às constantes invasões, migraram para a região da Bretanha, País de Gales e Irlanda. Já os contos maravilhosos teriam surgido no Oriente, mais especificamente na Índia do século VI. 
Além da diferença de origem, Nelly Novaes Coelho chama a atenção ainda para a problemática dessas histórias. No conto de fadas, a problemática seria existencial, voltada para o amadurecimento das personagens, as quais passam por uma situação de conflito, que deve ser superada.

Como num rito de passagem, quando completam sua aventura, as protagonistas deixam sua casa (geralmente o castelo do rei) e encontram a felicidade casando-se com o príncipe. Aqui a autorrealização está na relação amorosa homem-mulher. Nesse contexto, histórias como "Branca de Neve", "Cinderela", "A Bela e a Fera”, "O rei sapo ou Henrique de Ferro", "A Pequena Sereia", "Rapunzel" e "A Bela Adormecida" seriam exemplos de contos de fadas, embora a fada não apareça como personagem em alguns deles.

Nessa perspectiva, Marina Colasanti (2004, p. 221-2) afirma que a fada não é elemento obrigatório nessas histórias: "além do mais, ao contrário do que a denominação faz crer, as fadas não são sequer presença obrigatória nesses contos - -mais adequadamente chamados de contos maravilhosos - e, quando aparecem, não são personagens centrais." Vale ressaltar que a escritora, que defende aqui adotar o termo "conto maravilhoso" em detrimento de "conto de fadas", emprega ora um, ora outro indistintamente.

Quanto aos contos maravilhosos, segundo Nelly Novaes Coelho, a problemática é social, ou seja, o protagonista passa por problemas financeiros, enfrenta a pobreza, e sua autorrealização está na aquisição de bens e riquezas. Podem também apresentar o embate entre o bem e o mal. Nesse contexto, seriam contos maravilhosos histórias, como "O gato de botas", "João e o pé de feijão", "O Pequeno Polegar", "Ali Babá e os quarenta ladrões", "João e Maria". 
Já Cascudo (2012) que não faz distinção entre contos de fadas e contos maravilhosos, apresenta uma nova nomenclatura que englobaria ambos: contos de encantamento. Para esse autor, contos de encantamento são aqueles marcados pela presença do sobrenatural, com amuletos, virtudes supra-humanas, aventuras de príncipes, irmãos e auxílio do que é "extraterreno".

Para Nelly Novaes Coelho (1984, p. 122), o conto maravilhoso "é a narrativa que decorre em um espaço e tempo fora da realidade e onde os fenômenos não obedecem às leis naturais que nos regem." Já o conto de fadas, além de ser marcado pelo sobrenatural, relaciona-se ao "destino", pois, de acordo com a autora, essa narrativa encarna a possibilidade de realização dos sonhos, com interferência na vida dos personagens. Vale reforçar que a fada não precisa ser uma jovem encantadora, com asas e varinha de condão. Trata-se aqui de uma entidade mágica, de uma atmosfera criada nessas histórias, não necessariamente sendo uma personagem.

Posto isso, entendemos que contos de fadas e contos maravilhosos seriam dois gêneros distintos, porque a problemática, ou seja, o que desencadeia o conflito na vida dos protagonistas, é diferente. Vale reforçar que, quando nos referimos a esses contos de maneira indistinta, tratamo-los por contos de encantamento.

\section{NO LAGO}

Como mencionado anteriormente, a partir da modernidade, os contos de encantamento foram resgatados por diversos autores a partir da intertextualidade, especialmente por meio da paródia, a fim de satirizar essas produções. 
Embora possamos encontrar diversos elementos intertextuais nos contos de Marina Colasanti, percebemos que a escritora se dedicou a escrever contos de fadas originais e não apenas a construir contos intertextuais. Sobre isso, em entrevista concedida em 2016, a escritora afirma: "na modernidade, os autores costumam se acercar dos contos de fada ou através da paráfrase ou através da paródia. Nenhum dos dois me interessou" (COLASANTI, 2016).

Com vasta produção literária e não literária, Marina Colasanti é escritora, ilustradora, ensaísta, tradutora e foi jornalista. Escreve contos, crônicas e poemas tanto para o público adulto quanto infantil.

Entre os livros de contos de fadas da escritora, destacamos Uma ideia toda azul, -de 1979, Doze reis e a moça no labirinto do vento, de 1982, Entre a espada e a rosa, de 1992, Longe como meu bem querer, de 1997. Em 2015, foi lançado Mais de 100 histórias maravilhosas, que reúne toda a sua produção de contos de fadas, com 117 contos, sendo 17 deles inéditos, compondo o livro Quando a primavera chegar. Este foi lançado separadamente em 2017.

Se considerarmos o universo feérico, os contos de fadas de Marina Colasanti são construídos em reinos distantes, num tempo mítico, com reis, rainhas, princesas e príncipes, cavaleiros e camponesas sem nome, assim como costuma ocorrer nos contos de fadas tradicionais. Na entrevista concedida em 2016, a autora, afirma ainda que

faço contos maravilhosos absolutamente autorais e dentro do gênero (ou seja: narrativas fora do tempo cronológico e fora do espaço da realidade; de conteúdo denso permitindo múltiplos níveis de leitura; destinados a qualquer idade) (COLASANTI, 2016). 
No conto "A primeira só", objeto de análise aqui, a princesa é identificada como sendo "a linda filha de rei": "Era linda, era filha, era única. Filha de rei" (COLASANTI, 2006, p. 46). O conflito presente nessa narrativa está no fato de a princesa não ter ninguém com quem brincar e isso a deixava muito triste, pois se sentia solitária e isolada. Seu grande desejo era ter uma amiga. Essa história trabalha, portanto, com a ideia de solidão e confinamento, o que é muito comum nos contos de fadas tradicionais. Nessas histórias, a sensação de isolamento ou solidão não está tão evidente como nesse conto de Marina Colasanti, mas aparece de forma implícita.

Lembremos que Cinderela era maltratada pela madrasta e suas filhas: elas não poderiam ser consideradas, portanto, companhias para a protagonista. Branca de Neve teve de fugir do castelo, por causa de sua madrasta e passou a vagar pela floresta, enfrentando o desconhecido sozinha. Bela também enfrentou a solidão quando decidiu poupar seu pai e viver no castelo da Fera, que aparecia apenas à noite. Em Rapunzel, a solidão e isolamento seriam mais visíveis, embora o narrador não deixe transparecer o sentimento de vazio e dor que são evidenciados no conto "A primeira só". Nesse sentido, Maria Imaculada Cavalcante (2011, p. 2) expõe que esse conto "retrata a solidão de uma princesa fechada em seu castelo, presa dentro do quarto e dentro de si mesma, solitária e angustiada em sua condição de filha única do rei."

A fim de evitar a tristeza da filha, o rei decide chamar o vidraceiro e o moldureiro, que construíram um espelho que foi colocado em frente à cama da princesa. Quando a menina acordou, ficou muito feliz ao perceber que não estava mais sozinha. Havia uma perfeita harmonia e simetria na relação entre a princesa e sua nova amiga, que, na verdade, era seu reflexo. Um dia, brincando de bola com a amiga, a princesa jogou o brinquedo para o 
espelho, o que o deixou em pedaços. Quando ele se quebrou, a princesa pensou que sua amiga não estava mais com ela, e seu sentimento de dor e solidão voltou a abatê-la. Quando ia chorar, porém, ela viu nos cacos seu rosto refletido e novamente acreditou que fosse sua amiga, mas agora, essa amiga havia "trazido" novas amigas.

A filha de rei percebeu que ela podia ter mais de uma amiga e começou a quebrar os cacos do espelho em pedaços cada vez menores, para ter mais amigas. Entretanto, chegou um momento em que não era mais possível quebrar os cacos, pois eles já haviam-se transformado em pó, e finalmente a princesa voltou a ficar sozinha. Contudo, ela não queria mais ser única. A protagonista, então, deixou o palácio e correu pelo bosque até encontrar um lago. Quando ela se aproximou dele, "no reflexo da água a amiga esperava por ela" (COLASANTI, 2006, p. 49). A fim de alcançar sua amiga no lago,

[...] a linda filha do rei atirou-se na água de braços abertos, estilhaçando o espelho em tantos cacos, tantas amigas que foram afundando com ela, sumindo nas pequenas ondas com que o lago arrumava a superfície (COLASANTI, 2006, p. 49-50).

Dessa maneira, para não voltar à solidão e ao isolamento do castelo, a princesa decidiu jogar-se na água e morrer. Percebemos, aqui, que os contos de fadas de Marina Colasanti não possuem a previsibilidade dos contos de fadas tradicionais, sendo marcados pela quebra de expectativa. A morte da princesa no final da história rompe drasticamente o típico final em que as princesas "vivem felizes para sempre com seus príncipes". A morte é um elemento recorrente na literatura da escritora, entretanto ela é ressignificada, perdendo sua carga negativa. O mergulho na água seria um retorno às origens, ao útero materno ou ao renascimento da protagonista, pois a água, segundo -Jean Chevalier e Alain Gheerbrant 
(1997), simboliza três temas dominantes: é "fonte de vida", "meio de purificação" e centro de "regenerescência". A filha de rei encontra a si mesma e seus vários "eus" (as várias amigas) no momento em que mata a princesa solitária, que era filha única e que vivia só.

Outra diferença aqui é a ausência do príncipe, que costuma aparecer no final da história com a única função de trazer a felicidade eterna às princesas. A solidão das protagonistas nas versões tradicionais encerra-se com a chegada do príncipe e o matrimônio. É quando elas concluem o rito de passagem e alcançam a autorrealização. Já em "A primeira só", a possibilidade de autorrealização acontece com a chegada de uma amiga, e a problemática da história é redefinida, uma vez que não se limita à relação amorosa entre homem-mulher.

Aqui Marina Colasanti também desconstrói a visão negativa contra o estereótipo de inimizade entre as mulheres, uma marca do filme Frozen, que reforça o amor entre irmãs. Nesse contexto, os contos de Marina Colasanti

[...] são considerados contos de fadas modernos porque, diferentemente dos tradicionais, nem sempre os finais são aqueles que esperamos, são por muitas vezes felizes, mas não do jeito que imaginamos ou do jeito que estamos acostumados a ver (PAGOTO; RAMOS; WAGNER, 2013, p. 62).

Percebemos, portanto, que as personagens de Marina Colasanti são mais profundas, pois suscitam nos leitores a reflexão, o questionamento e, muitas vezes, são imagens simbólicas de subversão contra padrões sociais e estereótipos, principalmente porque são influenciadas pelas questões de gênero discutidas por movimentos feministas, -defendidas abertamente pela escritora.

Desse modo, vimos que o conto "A primeira só" trabalha com a ideia do isolamento e solidão e como isso influencia a formação da problemática nessa narrativa. A questão 
existencial nesse conto é a busca do outro, que se confunde com a procura de si mesma, visto que a princesa não se reconhece no espelho, não sabe quem é, até o momento em que decide mergulhar no lago e encontrar-se, como podemos perceber pela leitura do texto.

Bruno Bettelheim (1980) já defendia a leitura dos contos de fadas, reforçando que eles não tratam de condições da vida moderna, porém sua importância está no fato de tratarem dos problemas inerentes aos seres humanos (perdas, medo, dor, morte, separação) e, por isso, devem ser lidos. Em "A primeira só", são exatamente essas questões que são apreendidas pelos leitores mais atentos e sensíveis.

\section{CONSIDERAÇÕES FINAIS}

Ao longo deste trabalho, percebemos que os contos de encantamento são histórias muito antigas, de raízes nos ritos de passagem dos povos primitivos. Essas histórias foram alteradas e perderam seu caráter sagrado e verdadeiro, tornando-se ficção. Esses contos se desenvolveram em duas culturas distintas: uma oriental (Índia e Pérsia), dando origem aos contos maravilhosos, e outra céltica (Bretanha), originando os contos de fadas. Contudo, ambos são muito semelhantes, pois são histórias com magia, situadas num tempo e espaço imprecisos que parecem ter-se perdido na Idade Média, quando havia reis, rainhas, castelos, caçadores, cavaleiros e camponeses.

Eles passaram a incorporar o acervo da literatura infantil, que se desenvolve no final do século XVII. As versões tradicionais desses contos têm sido adaptadas e recriadas, sendo usadas como fonte de inspiração para novas histórias no cinema e na literatura. Quanto à produção literária, destacamos os contos de fadas modernos da escritora Marina Colasanti, os quais vão de encontro à expectativa dos leitores devido aos desfechos surpreendentes e 
abertos, estimulando a reflexão, visto que suas narrativas rompem com padrões e valores estereotipados pela cultura.

Acreditamos que os contos de fadas e os contos maravilhosos sempre serão atemporais e, portanto, podem ser lidos a qualquer momento, por qualquer pessoa, em qualquer idade, porque são narrativas que tratam do que é inerente aos seres humanos, ou seja, os sentimentos, os desejos, os medos, os sonhos, a perda, a curiosidade, a tristeza e a busca pela felicidade.

\section{REFERÊNCIAS}

ALBERTI, Patrícia Bastian. Contos de fadas tradicionais e renovados: uma perspectiva analítica. 2006. 130-f. Dissertação (Mestrado em Letras e Cultura regional) - Faculdade em Letras, Universidade de Caxias do Sul, Caxias do Sul, 2006. Disponível em:< http://tcde.ucs.br/tde-busca/arquivo.php?dodArquivo=329>. Acesso em: 02 -maio 2014.

ARIÈS, Phillipe. História social da criança e da família. Trad. Dora Flasksman. 2. ed. Rio de Janeiro: LTC, 1981. p. 39-67.

BETTELHEIM, Bruno. A psicanálise dos contos de fadas. 6. ed. Trad. -Arlete Caetano. Rio de Janeiro: Paz e Terra, 1980.

BRESCIANI, Lucimar. A leitura de contos de fadas e a proposta de conhecimento. 2010. 91f. Dissertação (Leitura e Cognição) - Programa de pós-graduação em Letras, Universidade de Santa Cruz, Santa Cruz do Sul, 2010. Disponível em: <http//www.unisc.br/portal/imagens/stories/mestrado>. Acesso em: 27 maio 2014.

CASCUDO, Luís da Câmara. Literatura oral no Brasil. São Paulo: Global, 2012. p. 13-24, 185197, 308-310.

CAVALCANTE, Maria Imaculada. Uma leitura da simbologia no conto "A primeira só", de Marina Colasanti. In: SIMPÓSIO INTERNACIONAL DE LETRAS E LINGUÍSTICA, 2, 2011, Uberlândia. Anais... Uberlândia: EDUFU, 2011. Disponível em: <http://www.ileel.ufu.br/anaisdosilel/wp--content/uploads/2014/04/silel2011 144.pdf>.

Acesso em: 30 maio 2018. p. 1-8.

CHEVALIER, Jean; GHEERBRANT, Alain. Dicionário de símbolos. Trad. Vera da Costa e Silva et al. 11. ed. Rio de Janeiro: José Olympio, 1997.

COELHO, Nelly Novaes. A literatura infantil. 3. ed. São Paulo: Quíron, 1984. 
O conto de fadas. 2. ed. São Paulo: Ática, 1991.

COLASANTI, Marina. "E as fadas foram parar no quarto das crianças". In: Fragatas para terras distantes. Rio de Janeiro: Record, 2004. p. 221-241.

Uma ideia toda azul. 23. ed. São Paulo: Global, 2006.

. Um olhar sobre Marina Colasanti. Brasil, 23 ago. 2016. Entrevista concedida a Neide Graça e a Mercedes Fernandes. Disponível em: https://www.marinacolasanti.com/2016/08/um-olhar-sobre-marina-colasanti.html\#more. Acesso em: 30 maio 2018.

DODO, Marlúcia Nogueira do Nascimento. De fadas e princesas: afetos femininos em Marina Colasanti. 2010. 132-f. Dissertação (Mestrado em Letras) - Programa de Pós-graduação, Universidade Federal do Ceará, Fortaleza, 2010. Disponível em: <http://www.repositorio.ufc.br>. Acesso em: 10 ago. 2014.

ELIADE, Mircea. Imagem e símbolos. Trad. Maria Adozinda Oliveira Soares. Lisboa: Arcádia, 1979. Disponível em: copyfight.me/. Acesso em: 13 mar. 2015.

MENDES, Mariza B. T. Em busca dos contos perdidos: o significado das funções femininas nos contos de Perrault. São Paulo: Editora UNESP/Imprensa Oficial do Estado de São Paulo, 2000. p. 21-31, 46-59, 123-129.

PAGOTO, Cristian; RAMOS, Drielly da Fonseca; WAGNER, Jacqueline Marcelli Cordeiro. "Entre leão e unicórnio: um conto de fadas moderno". Diálogos \& saberes. Mandaguari, v. 9, 2013. Disponível em: <http://seer.fafiman.br/index.php>. Acesso em: 25 jan. 2016. p. 61-74.

PERES, Ana Maria Clark. "Literatura infantojuvenil: para que fazer?". Suplemento literário, p. 3-9. -Disponível em:<http://www.cultura.mg.gov.br/file/2007-outubro-1306.pdf>. Acesso em: 10 out. 2015 (2007).

ZILBERMAN, Regina. "Literatura infantil: livro, leitura, leitor". In: (Org.). A produção cultural para a criança. 4. ed. Porto Alegre: Mercado Aberto, 1990. p. 93-115.

Artigo recebido em: 31 de maio de 2018. Artigo aprovado em: 11 de agosto de 2018. 